\title{
A STUDY OF PICTORIALMETAPHOR IN ADVERTISEMENTS
}

\author{
Huda Hussein Abdulla Asst.Prof.Manal Jasim Muhmmad (Ph.D) \\ University of Baghdad \\ College of Education for Human Sciences \\ IbnRushd Dept. of English
}

DOI: $10.37648 / \mathrm{ijrssh} . v 10 \mathrm{i} 03.012$

Received: $27^{\text {th }}$ May, 2020; Accepted: $18^{\text {th }}$ June, 2020; Published: $01^{\text {st }}$ July,2020

\begin{abstract}
Pictorial metaphors are one of the non-verbal metaphors that commonly appear in advertisements. These metaphors include source and target domains. When both of these domains are visually represented, they are called monomodal. Whereas when verbal representation is used with visual one, they are called multimodal. Pictorial metaphors can be contextual when only one domain is visually represented and the other is contextually known. Pictorial metaphor can also besimile when both domains express the point of similarity between them, or hybrid when the source and target domains are mixed. This paper aims to identify the use of pictorial metaphor in American and British advertisements and show how they are similar or different. To achieve the aims of the study, an eclectic model of Forceville's (1996) and Evans and Green's (2006) is used to analyze 10 selected American and British advertisement.The analysis of data revealsthat there are some similarities and differences in American and British pictorial metaphor advertisements. It also concludes that hybrid pictorial metaphor is the most repeatedly used in pictorial metaphor in both American and British advertisements.

Key words: pictorial metaphor, advertisement, American ads, British ads, visual metaphor
\end{abstract}

\section{INTRODUCTION}

Metaphors can deliver meaning from one subject to another without using language because it can be only visual one. In this regard, Kittay (1987:14) asserts that metaphor is not found only in language and it is not merely linguisticsbecause metaphors are found in music, in films, in dance, in painting, or in any other expressive mediums, Whereas, other scholars have been more cognitively oriented such as Kaplan (1992:198). In this regard, MacCormac (1985:12) defines metaphor from the cognitive perspective as a knowledge process, therefore, he thinks that speaking of metaphor as a knowledge process means including the cognitive activity of the mind, the interaction of the mind with its environment and the activities of the brain on which the mind depends for its operations. Similarly, MacCormack(1985:127) states that in surface language, metaphors appear as linguistic devices. Yet, the intentional ability to suggest a new meaning originates in a cognitive process. The human mind combines concepts that are not normally associated to form new concepts. This cognitive activity works consciously and unconsciously.

The majority of these studies have concentrated on verbal metaphor. However, metaphor is a matter of thought before being a matter of language. Therefore,this study aims study metaphor in its non- 
verbal form. Pictorial metaphors are one of these nonverbal metaphors that commonly appear in advertisements whether in British of American ones. Social and cultural metaphors can be used and understood as part of everyday communications(Lakoff\& Johnson, 1980: 4). One of these everyday communication is the growing use of pictorial metaphors in British of American advertising which calls for investigating and analyzing such a usage.

\section{LITERATURE REVIEW: METAPHOR}

The beginnings of the study of metaphor can be traced back to old Greece, basically Aristotle (fourth century b. c.) who regards metaphor as an understood comparison which is based on analogy (Ortony, 1979, $3)$.

Aristotle is one of the earliest scholars who have dealt with metaphor. To Aristotle, words are mainly signs or images that express thoughts. The more words are combined, are given symbolized meanings to the more complicated ideas (ibid).Metaphor is traditionally seen as a figure of speech generally utilized in literature and specifically inpoetry. Usually a metaphor is taken from the everyday use of language.

Martin and Harre (1982: 90) argue that metaphor shapes the premise of the so-called comparison hypothesis of metaphor. This approach sees metaphor as "a kind of comparison, a condensed simile" based on closeness hence, the metaphor: you are the light in my life is considered as a small adaptation of: You are just like the light in my life.

The downside of this viewpoint is that it disregards the imperative contrast between a comparison and a categorization whereas a contrast emphasizes strong similarities of pair concepts, a metaphor builds of the pair ideas as having "in common something more than simple likenesses in that they have a place to the same category sharing important features" (Cacciari, 1998: 135). The second major hypothesis is the substitution hypothesis of metaphor. As far as this is in concerned "metaphor could be a way of saying what may well be said literally" (ibid). In other words, metaphor can be substituted by using a synonymous exacting expression. (Werner, 1975: 15).

The third broadly held approach to metaphor, established by Black (1979) within the second half of the twentieth century, is the interaction hypothesis of metaphor. Opposite to the comparison and the substitution hypotheses, it does not deal with metaphor as simply expressing metaphorically something that might have been said truly, but rather as building unused implications.

\subsection{The Conceptual Metaphor}

The study of metaphor had a new direction since Lackoff and Johnson published their book"Metaphors We Live By" in 1980. This new direction of metaphor concentrates on the conceptual representation that has an important role in the way we think about the world. Conceptual Metaphor Theory (henceforth CMT) considers that the existence of metaphor is in our thought and language. The richness of CMT is that there is a list of systematic correlations which are known metaphorical mappings to deal with conceptual domains (source and target) which exist in everyday language (Weisberg, 2012: 10).

An opposition to the classical view of metaphor is presented in the CMT originated by Lakoff and Johnson (1980:29) in the following points:

1. By metaphor, one reaches abstract reasoning by comprehending abstract concepts.

2. Metaphor allows one to comprehend an abstract item in terms of another that is extremely structured.

3. Metaphor is regarded alive, unconscious and automatic

4. Metaphorical mappings are stable in nature.

5. Metaphorical mappings can be widespread, universal or culture-specific.

A conceptual metaphor is defined, according to Cognitive Linguistics, as a mental method that permits one to comprehend abstract and complicated notions in terms of simple ones. This procedure includes mappings between two domains in the mind. (Lakoff and Johnson, 1980: Forceville, 2009).The item 'mapping' is used in mathematics to refer to the process of matching each item of the domain with a certain number. In the CMT, mapping refers to "systematic metaphorical correspondences between closely related ideas" (Grady, 2007:190). 


\subsection{Pictorial Metaphor}

Metaphors or comparisons can be depicted by the work of visuals instead of words. An ability to make such assessment is often very valuable from a commercial advertiser. Visuals in commercial are used to be the essential part of an advertisement to attract the target's attention (Pieters\& Wedel, 2004:109).

In addition, Sullivan (2008:54) says that one is capable to try and do a lot of with pictures than with words. Forceville (2009:97) states that the non-verbal manifestations regarding conceptual metaphors have not been well investigated by some researchers including the conceptual metaphor theory of Lakoff and Johnson (1980). Lakoff claims that, the knowledge that shapes conceptual schemas is incompletely verbal, however not exclusively. Thus, there are two domains for a metaphor a source and target one that belong to distinctive modes, that is, they can be multimodal. Image metaphor is a metaphor that connects one concrete object to another concrete object, as in the sentence "Her spread hand was a star fish" is a relatively modern term and has not been theorized as much as metaphor as a whole. The term is coined by Lakoff\&Turner (1989, 219) and Gibbs (1994: 258-60). They argue that image metaphors are variations within metaphor larger rule, "you can say with one image what you might need 20 words to say. Visuals get a lot of work done quickly and simply" (Sullivan, 2008: 61).

\subsubsection{Types of Pictorial Metaphor}

According to Forceville (2009:50) there are four types of pictorial metaphor:

i. Contextual pictorial Metaphor: in this metaphor, the context usually helps in inferring one term whereas the other already exists, by the help of pictorial context, the audience cancomprehend the metaphor. When the pictorial context is removed, the metaphor cannot be recognized. Forceville's example "STRIKE IS BAR OF $S O A P$ " Cleanser (Figure 1) shows Lucky Strike cigarettes as the target space of the metaphor, within the bar of cleanser place (the source space). In spite of the disappearance of the bar of soap, the rest of the picture emphatically recommends it.

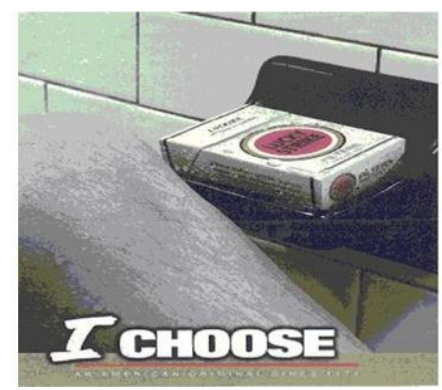

"Figure 1: Lucky $\mathbf{S}$ is Bar of Soap"

ii. Hybrid Metaphor, when a thing contains components of both terms presented pictorially. In these types of metaphors, the target domain is apparently mixed with the source domain. The audience can distinguish both of them but cannot separate them. Both the target and the source make a single gestalt. According to Forceville, if the pictorial setting is removed, the target and the source can still be recognized, even with the removal of the verbal context. Forceville's outline "THE COMPUTER COMPONENTS ARE NOTES IN A MELODIC COMPOSITION" (Figure .2) has the notes as the source domain that can be recognized as the stems and the melodic score and the computer components as the target domain of the metaphor, appears up as the note heads. So both the notes and the computer components make a hybrid pictorial metaphor.

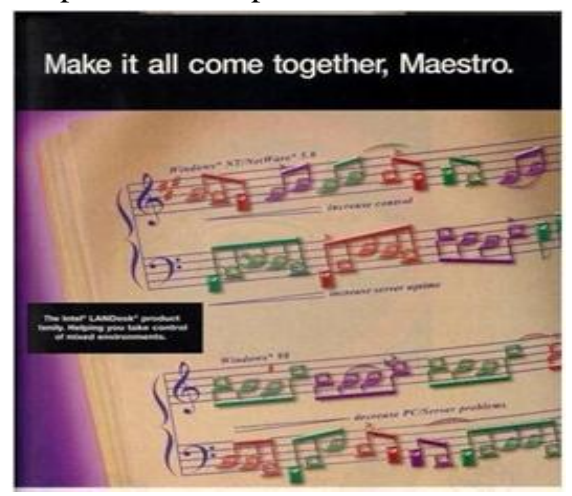

Figure 2. Computer Components are Notes in a Musical Composition, Advertisement in PC Magazine (1999)

iii. Pictorial simile is the case in which two dissimilar terms in terms of domain appear up, they would be compared in a picture in a way that makes the audience understand one in terms of the other. They are presented in a juxtaposed image. The target and the source domains are saliently compered. There are many means to make such kind of metaphor visually; for example describing 
the target and the source in the same attention or showing them in the same context. Forceville's example

DOMMELSCH BEER IS (LIKE) LEANING TOWER OF PISA (Figure, 3) shows up the target domain (the Beer) and the source domain (the Tower). One of the highlights the maker proposes can be mapped from the source to the target is "reason for national pride".

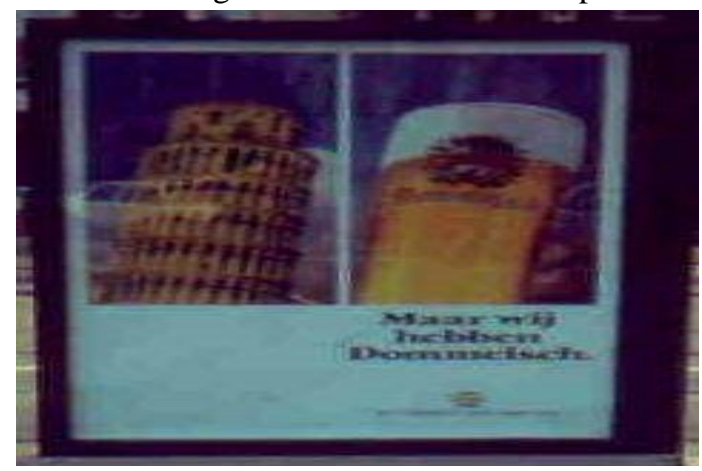

"Figure 3.Dommelsch Beer is (like) leaning tower of Pisa"

iv. "Integrated metaphor", in which the source and the target presented as a unified entity in a way that is physically conceivable, indeed with no relevant imply. In this kind of metaphor the target presumes important features of something else (the source), with the aim of bringing formal features connected with the source into the target. Forceville's case, SENSEO COFFEE MACHINE IS SERVANT (PHILIPS) (Figure. 4) distinguishes (the target space) represented by the machine from the source space represented by a hireling who twists while advertising a container of coffee on a plate.

One can notice the similarity of this type of metaphor and the hybrid metaphor, but there is an important difference; whereas the hybrid metaphors describe non existing gestalts in the real world, the integrated metaphor appear physically in the real world.

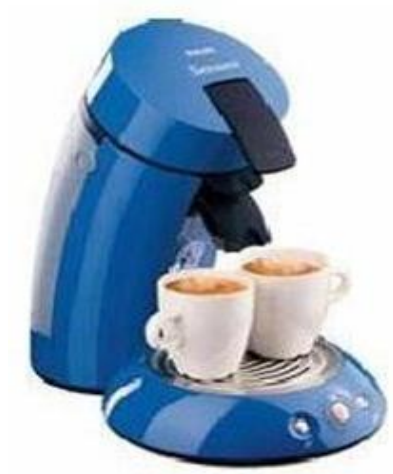

"Figure 4.Senseo coffee machine is servant (Philips)".

\subsection{Multimodal Metaphor}

Forceville (2009:102) refers to the challenge of limiting what is related to a specific mode as the border area units are generally fuzzy: what is believed to be a sort of music in one culture might not be considered within the same means by another culture.

Spoken language has special conditions as signing. Forceville makes a distinction between the following different modes: speech, written language, non-verbal sound, music, pictures, smell and taste. Yet, he also notices that these modes can be further divided as they represent terribly wide concepts: footage, for instance, would encompass static or moving pictures, drawings, diagrams or photographs. Since the method of transferring the message restricts the modes that will be used.

In dealing with the mode (either in multimodality or monomodality) the medium used ought to be considered. In this regard, Kress (2010:29) suggests that each mode has been selected to convey certain ideas and the writer relation with the target addressees is reflected in theselection of the mode; the result can reflect particular aesthetics that convey cultural and social implication. It is shown that multimodality entails the use of more than mode,whereasmonomodality alludes to messages observed solely by one. Within allegories, Forceville (1996: 16) suggests that metaphors can be regarded as multimodal when the source and the target are transferred "exclusively or transcendently in two distinctive modes". Combining verbal and pictorial metaphors is common in most magazine notices. 


\section{4 Image Schemas}

The concept schema was first outlined by the Swiss psychologist Jean Piaget in 1923.Piaget defined image schema as mental units that are related to the all aspects of the world. Schema can help people to understand and interpret new information. One of the most important things about image schemas is that they underlie all aspects of meaning and cognition and hence they motivate important aspects of how people think, reason and imagine. It can therefore play a very important role in persuasion. Nevertheless, in spite of this importance, they have not yet been sufficiently explored. As argued by Gibbs (1994), "they are a crucial, undervalued dimension of meaning". Advertisers believe that image schemas are useful in attaining the goal of persuading and influencing the target audience. Image schemas are based in the bodily experiences. They cover schemas such as "front-back", "in- out", "inside-outside" .Almost all human beings share image schemas. Scholars agree that it is very difficult to define image schema and to determine the exact number of image schemas (Clausner and Croft, 1999: 21; Oakley, 2007: 229; Szwedek, 2019:20). Defining an image schema requires distinguishing between image schematic domains and non-imagistic domains (Clausner and Croft, 1999: 14). Besides that, the boundary between abstract and concrete image schemas should also be determined. Szwedek(2019:20) tries to find a definition of image schema . He says that the image schema is:

" a mental structure with at least one OBJECT image schema, which is a conceptually independent entity representing a physical object whose fundamental property is density experienceable by touch, with ensuing boundedness, shape, size, etc."

In defining image-schema, it is essential to define "image", "schema" as separate items and "image schema" as a compound item. Oackley (2007:215-216) states that schema is "a way of relating percepts to concepts ". He adds that "Schemas are fixed templates superimposed onto perceptions and conceptions to render meaningful representations".

Johnson (1999:282) defines a schema as "a mental framework based on past experience developed as a means of accommodating new facts, and hence making sense of them". Then Oackley (ibid) discusses that image "implicates perception in all acts of conceptualizations", adding that "images are always analogue representations of specific things or activities". Items develop from perceptual representations of visual, auditory and gustatory experiences.

As a compound concept, image schema is clarified by Johnson (1987:21) as

"Image schematic structure emerging from our experience of physical containment and boundedness is one of the most pervasive features of our bodily experience. It is a spatial pre conceptual configurations that arise from everyday bodily experience".

Additionally the most important thing about image schema is that by image schema people can shape structures, which are used to form thoughts along a range of abstract domains. This shaping depends on the human physical experiences in the world. Image schema deals with the use of the stored images to conceptualize new items, depending on the previous knowledge (ibid).

In cognitive linguistics, image schemas are "gestalt structures, consisting of parts standing in relations and organized into unified wholes, by means of which our experience manifests describable order ... without which our experience would be chaotic and incomprehensible". (Johnson, 1987:19).

Johnson and Johnson (1999:282) state that image schema is "a mental framework based on past experience developed as a means of accommodating new facts". It can be understood as an embodied prelinguistics structure of experience that activates conceptual mapping that helps to understand the world. Johnson (2005:16) states that "the structures of perceiving and doing must be appropriated to shape our acts of understanding and knowing. Our sensory-motor capacities must be recruited for abstract thinking".

In metaphor image schema plays a crucial role as image schema metaphor somewhat map from source to target. This is because of the skeletal image schema that such kind of metaphor has. Physical experience which is obtained from the world interactions, give rise to what is named image schema. Advertisers make use of image schemas because of the persuasive nature that they have. 


\subsection{Advertisements: General Remarks}

The original meaning of advertisement was to take note or to consider something but later it is modified to persuading. Creating a positive image of a product, a particular brand that matches the figure or motive of the possible buying public, or a certain service is the aim of advertisement. As an act of communication, advertisement aims at persuading the costumer to buy services or goods. Advertising companies are developing and have developed new non-verbally and verbally strategies and techniques because the goal of advertisements is to persuade the target audience. Both the non-verbal and the verbal modes have been created to be very compelling and attractive. For instance, it is noticed that advertising companies indicate to a myth which there in the society by using an image to make the advertisement more attractive. No doubt, this is done to convince the general audience to buy the product (Bignell, 2002: 26).

Recently there has been a concentration on metaphor and its use in the studiesof language of advertising. The ways of using metaphor in advertisement have been viewed differently. The semiotics approach has been adopted by a group of researches (Williamson, 1978; Dyer, 1988; Vestergaard\&Schrøder, 1985). While others have been cognitive in which scholars have paid more attention to investigate the recognition of metaphor whether linguistically and non-linguistically (Morris, 1993; Carroll, 1996; Goatly, 1997:30;Forceville, 1996 \& 2009; Ungerer, 2000;Dąbrowski, 2000).Finally , another group of studies has been linguistic such as Cook (1992); Hermerén (1999) and Tanaka (1994).

Semiotics and cognitive theories are concerned with meaning construction, like the pictorial and conceptual metaphor theories, or the conceptual blending theory, which focuses on various aspects of conceptualization. However, Scholars have noticed that they are complementary to one another. Metaphors are relevant to the discipline that studies advertising because metaphors are "laden with symbols and imagery that might be used creatively in implementing decisions that will animate or bring appropriate reasoning processes and mental models to life". (Stern ,1990: 38).

\subsection{Pictorial Metaphor and Advertisements}

The use of pictorial metaphors in advertisements is a matter of persuading the people of something with minimum use of words. The focus here is mostly on the effect of media on the way people think of mental structure and the way they conceptualize abstract, complex domains. For example their age, human relations, etc. According to current theories, metaphor plays a vital role in cognitional processing, influencing our reasoning, thinking and actions. As Lakoff and Johnson (1980:4) originally said, "Our ordinary conceptual system, in terms of which we both think and act, is fundamentally metaphorical in nature".

Kövecses (2010: 59) lists advertisements among the non-linguistic realizations when he explains these realizations of conceptual metaphors, advertisements are essential manifestations of conceptual metaphors. The ability to sell by advertising depends on the correct selection of the conceptual metaphor in that the pictures and the lexical items of the advertisements try to affect people. A suitably designated metaphor can greatly promote the sale of a product.

With the appearance of cognitive linguistics nearly thirty a long time back and particularly the work produced by Lakoff\& Johnson (1980), the interest of metaphor is increased. Inside this system, metaphor is viewed as a conceptual prepares that plays an important role in the organizing and categorization of the world around us.

More focus has been put on pictures instead of words over the past years within printed advertisements (Pollay, 1985:34; Phillips et.al, 2004; Anaya, 2008). After being an information tool, now text serve as an explanation of the mean idea on the advertisement (Baker, 1988:65). Many advertisers explain the content of their ads through "artful deviations from audience expectation" in order to expand creativity in advertisements (Phillips et al., 2004). These strategies include schemes which are artificial observations that are easily identified. Opposite to schemes, tropes are considered meaningful deviations that require extra effort, due to their incongruence between what is meant and what are pictured (van Enschot, Broekhuizen, \&Kolthoff, 2015).Tropes are harder to comprehend compared to schemes because they need cognitive processing. An example of a classical trope is metaphor. 


\subsection{British vs. American advertisements}

Although the persuasion of consumers to buy products is crucial aim in both American and British advertisements, still there are differences between them. These differences can be first seen in television commercials which can be considered as the basic means of advertisement in both countries. However, with the appearance of new means such the internet and the digital video recorders, new strategies are adopted by advertisers in order to persuade consumers. (Homer, 2008:13).

Except for public broadcasting stations or movie networks, In America, people have never had commercials besides television. One is regarded synonymous with the other. This this is not often the

\subsection{Data Analysis}

\subsubsection{American Pictorial Metaphors}

\section{Racism}

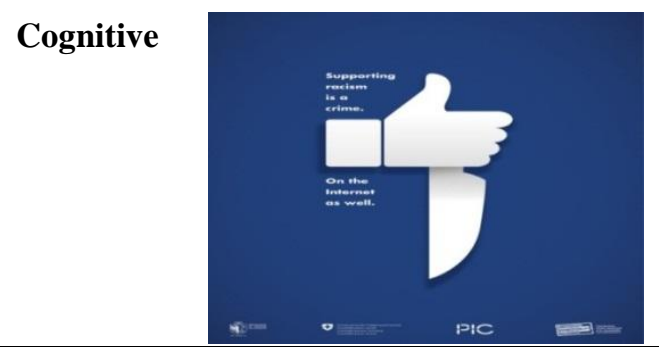

\begin{tabular}{|c|c|c|}
\hline \multicolumn{2}{|l|}{ Theme } & Racism \\
\hline \multicolumn{2}{|c|}{ Metaphor } & Facebook likeness sign is a killing knife. \\
\hline \multicolumn{2}{|l|}{$\mathrm{S}$} & The knife \\
\hline \multicolumn{2}{|l|}{$\mathrm{T}$} & Likeness sign \\
\hline \multicolumn{2}{|l|}{ SR } & Visual \\
\hline \multicolumn{2}{|l|}{ TR } & Visual \\
\hline \multicolumn{2}{|c|}{ Modality } & Monomodal \\
\hline \multicolumn{2}{|c|}{ Verbal reinforcement } & Supporting racism is a crime on the internet as well \\
\hline \multicolumn{2}{|c|}{ Features } & The knife and the likeness sign are mixed \\
\hline \multicolumn{2}{|l|}{ Type } & hybrid pictorial metaphor \\
\hline \multirow{4}{*}{$\begin{array}{l}\text { Image } \\
\text { Scheme }\end{array}$} & Force & Enablement \\
\hline & Attribute & dark-bright, strong-weak \\
\hline & Space & straight-curved, up-down \\
\hline & Multiplicity & part-whole \\
\hline
\end{tabular}

This image shows that the target domain is the likeness sign while the knife is the source domain, forming the connection between them with the connection of using a knife and using a likeness sign. As it can be noticed, the target and source 
domains are symbolized visually. Since the knife and the likeness sign are integrated to make a single object, this ad is a case of hybrid pictorial metaphor. The image of likeness utilized as a knife has been reproduced in thisadvertisement since the aim is to let the audience knows that knives can be used symbolically through using racist words in social media.

\section{Brandt}

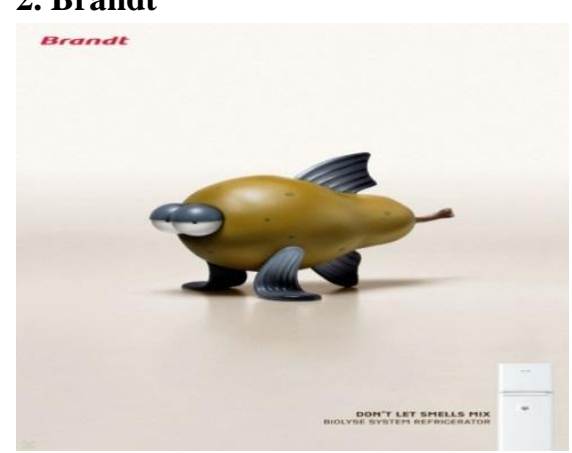

\section{Cognitive analysis}

\begin{tabular}{|c|c|c|}
\hline \multicolumn{2}{|l|}{ Theme } & Brandt \\
\hline \multicolumn{2}{|c|}{ Metaphor } & Pear is fish, fish is pear \\
\hline \multicolumn{2}{|l|}{$\mathrm{S}$} & Fish, Pear \\
\hline \multicolumn{2}{|l|}{$\mathrm{T}$} & Fridge. \\
\hline \multicolumn{2}{|l|}{ SR } & Visual \\
\hline \multicolumn{2}{|l|}{ TR } & Visual \\
\hline \multicolumn{2}{|c|}{ Modality } & Borderline case \\
\hline \multicolumn{2}{|c|}{ Verbal reinforcement } & Don't let smells mix \\
\hline \multicolumn{2}{|l|}{ Features } & The target is mixed with the source \\
\hline \multicolumn{2}{|l|}{ Type } & Hybrid \\
\hline \multirow{4}{*}{$\begin{array}{l}\text { Image } \\
\text { Scheme }\end{array}$} & Force & attraction, resistance \\
\hline & Attribute & strong-weak, dark-bright, big-small \\
\hline & Containment & in-out \\
\hline & Space & front-back, center-periphery, near-far \\
\hline
\end{tabular}

It is shown in this example that the source domains are the fish and the pear, while the target domain is the fridge. The message of this ad is that this fridge is different from other fridges as it does not allow the smell of things mix. So "Don't let smell mix" represents "Don't let things mix". This is represented visually by the use of metaphor .This image is a hybrid pictorial metaphor according to Forceville (1996) as it contains two different things(pear and fish) which are connected to form a single object. In this type of metaphor one can interpret one item in terms of the other. One can note that the verbal part in this ad is not a part of the metaphor but it is used in helping the audience to comprehend the required message. 


\section{Anti- Smoking}

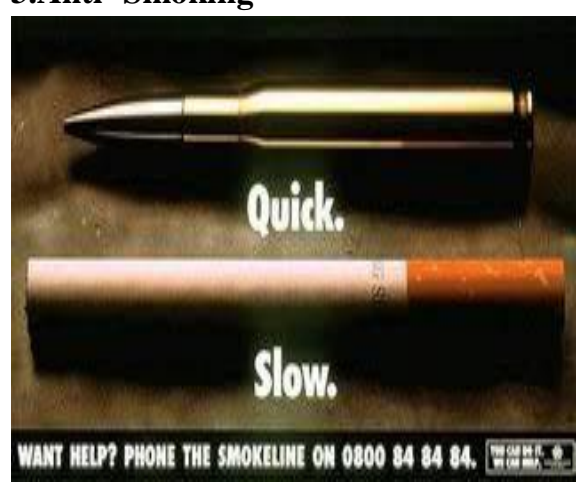

Cognitive analysis:

\begin{tabular}{|c|c|c|}
\hline \multicolumn{2}{|l|}{ Theme } & YOU CAN DO IT / Poop.com \\
\hline \multicolumn{2}{|c|}{ Metaphor } & Cigarette is a bullet \\
\hline \multicolumn{2}{|l|}{$\mathrm{S}$} & Quick death "bullet". \\
\hline \multicolumn{2}{|l|}{$\mathrm{T}$} & Slow death "cigarette". \\
\hline \multicolumn{2}{|l|}{ SR } & Verbal/ visual \\
\hline \multicolumn{2}{|l|}{ TR } & Visual/ visual \\
\hline \multicolumn{2}{|c|}{ Modality } & Multimodal \\
\hline \multicolumn{2}{|c|}{ Verbal reinforcement } & WANT HELP? PHONE THE SMOKELINE ON 0800848484 \\
\hline \multicolumn{2}{|l|}{ Features } & $\begin{array}{l}\text { Showing the similarity between a bullet and a cigarette in that both } \\
\text { lead to death }\end{array}$ \\
\hline \multicolumn{2}{|l|}{ Type } & Simile \\
\hline \multirow{3}{*}{$\begin{array}{l}\text { Image } \\
\text { Scheme }\end{array}$} & Force & Compulsion \\
\hline & Attribute & dark-bright \\
\hline & Space & near-far center-periphery, up-down \\
\hline
\end{tabular}

In this ad, both the source and the target domains are visually and verbally represented. Thus, the metaphor is multimodal. The verbal reinforcement "WANT HELP? PHONE THE SMOKELINE ON 0800848484" is used to invite the audience to get help by calling on the number above. Besides, the word "slow" points to cigarette as a slow death unlike "quick" bullet which means quick death. So, the ad's intended message is that the audience should avoid smoking and should think of the bad results of smoking and should get help to stop smoking.

\section{Social Media Danger}

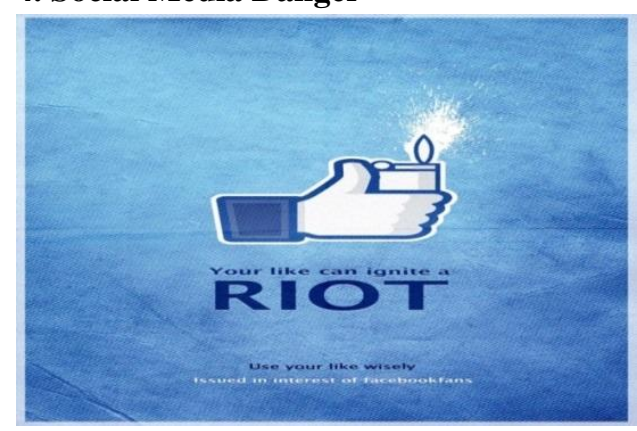




\section{Cognitive analysis:}

\begin{tabular}{|c|c|c|}
\hline \multicolumn{2}{|l|}{ Theme } & Social Media Danger \\
\hline \multicolumn{2}{|l|}{ Metaphor } & The Facebook like ignites a riot. \\
\hline \multicolumn{2}{|l|}{$\mathrm{S}$} & The lighter. \\
\hline \multicolumn{2}{|l|}{$\mathrm{T}$} & Likeness sign \\
\hline \multicolumn{2}{|l|}{ SR } & Visual \\
\hline \multicolumn{2}{|l|}{ TR } & Visual \\
\hline \multicolumn{2}{|l|}{ Modality } & Monomodal \\
\hline \multicolumn{2}{|l|}{ Features } & The target is mixed with the source \\
\hline \multicolumn{2}{|l|}{ Type } & Hybrid \\
\hline \multirow{3}{*}{$\begin{array}{l}\text { Image } \\
\text { Scheme }\end{array}$} & Force & compulsion, diversion, counterforce \\
\hline & Attribute & dark-bright, big-small \\
\hline & Space & up-down, center-periphery, straight-curved \\
\hline
\end{tabular}

The analysis of the image above shows that the likeness sign is the target domain whereas the lighter is the source domain, making the connection between them with the connection of using likeness sign and the lighter. The verbal statement "Use your like wisely" can not be considered as part of metaphor as both the target and source domains are visually symbolized. Because the likeness sign and lighter are integrated to make a single object, this is a hybrid pictorial metaphor. Finally, the message of this ad is to draw the attention of the audience to the danger of using 'like' unwisely on social media, providing riot with 'like' implies one ignites riots.

\section{TABASCO}

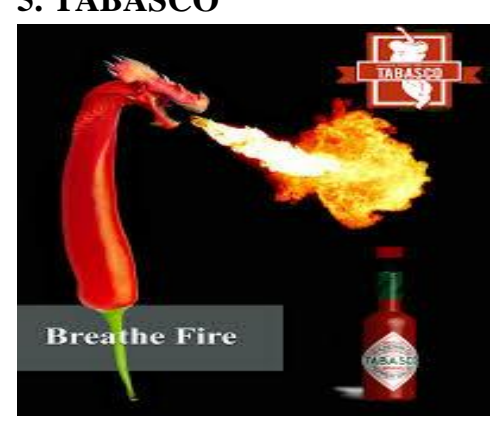

Cognitive analysis

\begin{tabular}{|c|c|c|}
\hline \multicolumn{2}{|l|}{ Theme } & Tabasco \\
\hline \multicolumn{2}{|c|}{ Metaphor } & Pepper is fire. \\
\hline \multicolumn{2}{|l|}{$\mathrm{S}$} & Fire. \\
\hline \multicolumn{2}{|l|}{$\mathrm{T}$} & Pepper. \\
\hline \multicolumn{2}{|l|}{ SR } & Visual \\
\hline \multicolumn{2}{|l|}{ TR } & Visual \\
\hline \multicolumn{2}{|c|}{ Modality } & Monomodal \\
\hline \multicolumn{2}{|c|}{ Verbal reinforcement } & Breathe fire \\
\hline \multicolumn{2}{|l|}{ Features } & The pepper is mixed with the fire \\
\hline \multicolumn{2}{|l|}{ Type } & Hybrid \\
\hline \multirow{4}{*}{$\begin{array}{l}\text { Image } \\
\text { Scheme }\end{array}$} & Force & attraction-resistance \\
\hline & Attribute & warm-cold, dark-bright, big-small \\
\hline & Containment & in-out \\
\hline & Space & straight-curved, up-down, near-far, front-back-right \\
\hline
\end{tabular}


This advert describes that the fire which the dragon blows is the source domain, while the bottle of pepper or the pepper is the target domain. The mapping is made between the source and the target as the audience knows pepper in terms of fire. Additionally, there is a verbal part "Breath Fire" which is not considered as part of the metaphor as both the target and the source are represented visually .

\subsubsection{British Pictorial Metaphors}

\section{Autostrade}

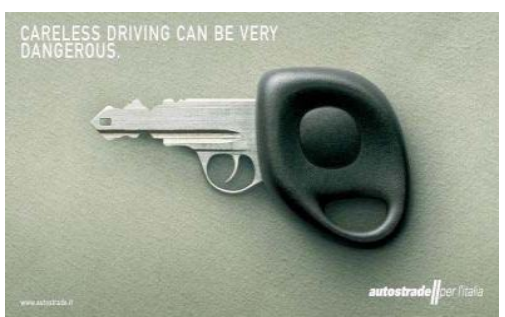

Cognitive analysis:

\begin{tabular}{|c|c|c|}
\hline \multicolumn{2}{|l|}{ Theme } & Autostrade \\
\hline \multicolumn{2}{|l|}{ Metaphor } & Careless driving can be very dangerous. \\
\hline \multicolumn{2}{|l|}{$\mathrm{S}$} & The gun \\
\hline \multicolumn{2}{|l|}{$\mathrm{T}$} & Switch key \\
\hline \multicolumn{2}{|l|}{ SR } & Visual \\
\hline \multicolumn{2}{|l|}{ TR } & Visual \\
\hline \multicolumn{2}{|l|}{ Modality } & Monomodal \\
\hline \multicolumn{2}{|l|}{ Features } & The source (gun) and the target(key) are mixed \\
\hline \multicolumn{2}{|l|}{ Type } & Hybrid \\
\hline \multirow{5}{*}{$\begin{array}{l}\text { Image } \\
\text { Scheme }\end{array}$} & Force & attraction-compulsion \\
\hline & Attribute & dark-bright, strong-weak \\
\hline & Balance & point balance equilibrium \\
\hline & Space & left-right, straight-curved \\
\hline & multiplicity & part-whole \\
\hline
\end{tabular}

In this ad, the target domain is the switch key while the source domain is the gun. The verbal statement in the ad "CARELESS DRIVING CAN BE VERY DANGEROUS" is not part of the metaphor as the source and target domains are represented visually. As the gun and switch key are integrated to make a single object, this is a hybrid pictorial metaphor. The intended message of this ad is that people have to be careful about their driving to avoid accidents and to save lives.

\section{Social media bullying}

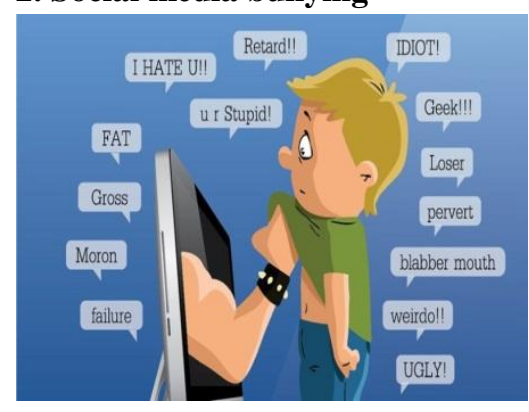


Cognitive analysis

\begin{tabular}{|c|c|c|}
\hline \multicolumn{2}{|l|}{ Theme } & Social media bullying \\
\hline \multicolumn{2}{|c|}{ Metaphor } & Negative words on social media are kinds of body violence. \\
\hline \multicolumn{2}{|l|}{$\mathrm{S}$} & The raised hand. \\
\hline \multicolumn{2}{|l|}{$\mathrm{T}$} & The boy in front of the screen \\
\hline \multicolumn{2}{|l|}{ SR } & Visual \\
\hline \multicolumn{2}{|l|}{$\mathrm{TR}$} & Visual \\
\hline \multicolumn{2}{|l|}{ Modality } & Borderline case \\
\hline \multicolumn{2}{|l|}{ Features } & One element is shown \\
\hline \multicolumn{2}{|l|}{ Type } & Contextual \\
\hline \multirow{5}{*}{$\begin{array}{l}\text { Image } \\
\text { Scheme }\end{array}$} & Force & compulsion ,blockage, enablement \\
\hline & Attribute & big-small, strong-weak, heavy-light \\
\hline & Containment & part-whole \\
\hline & Balance & Point balance equilibrium \\
\hline & Space & straight-curved \\
\hline
\end{tabular}

In this pictorial ad, the source is the raised hand while the target is the boy. The verbal part "UGLY - weirdo - blabber mouth- pervert-Loser-Geek-IDIOT- Retard- I HATE U-u r Stupid-FAT- Gross- Moron - failure "assists the audience to link the target and the source. The intended message of this ad is to raise the awareness of people of the risk of the cyber bullying. As it is noticed, the use of the verbal reinforcement is not part of the metaphor. The metaphor is put between monomodality and multimodality.

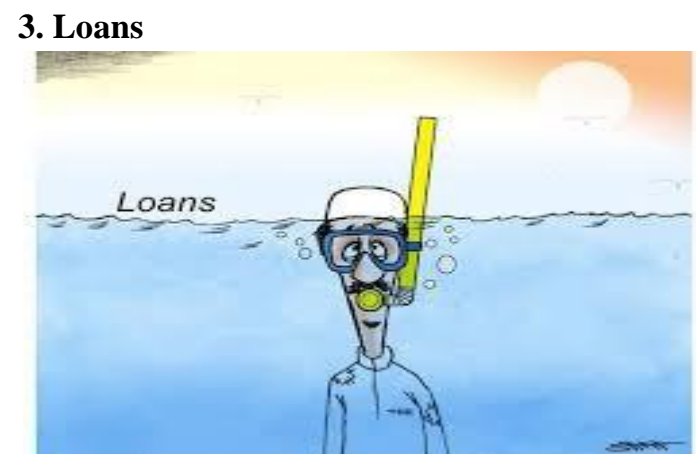

\section{Cognitive analysis}

\begin{tabular}{|c|c|c|}
\hline \multicolumn{2}{|l|}{ Theme } & Loans \\
\hline \multicolumn{2}{|c|}{ Metaphor } & Loans are a deep sea. \\
\hline \multicolumn{2}{|l|}{$\mathrm{S}$} & Sea \\
\hline \multicolumn{2}{|l|}{$\mathrm{T}$} & Loans \\
\hline \multicolumn{2}{|l|}{ SR } & Verbal \\
\hline \multicolumn{2}{|l|}{ TR } & Visual \\
\hline \multicolumn{2}{|l|}{ Modality } & Multimodal \\
\hline \multicolumn{2}{|l|}{ Features } & Only one element is shown while the other is known by context \\
\hline \multicolumn{2}{|l|}{ Type } & Contextual \\
\hline \multirow{5}{*}{$\begin{array}{l}\text { Image } \\
\text { Scheme }\end{array}$} & Force & Resistance \\
\hline & Attribute & dark-bright, big-small, heavy- light \\
\hline & Containment & in-out \\
\hline & Balance & axis-balance \\
\hline & Space & up-down, center-periphery \\
\hline
\end{tabular}


In this ad, the source domain is represented visually (the sea) while the target is represented verbally (Loans).As the two domains are presented in different modes (visually and verbally) the metaphor is classified as multimodal metaphor. This image is mapped in a cognitive way. The above ad describes a man with a snorkeling apparatus in the middle of the sea. $\mathrm{He}$ is in his torn clothes as a sign of his financial problems. The word 'loans' is also written on his seawater. In the two situations, the man is suffering: in the situation of the sea and in situation of the loans.

\section{Heinz}

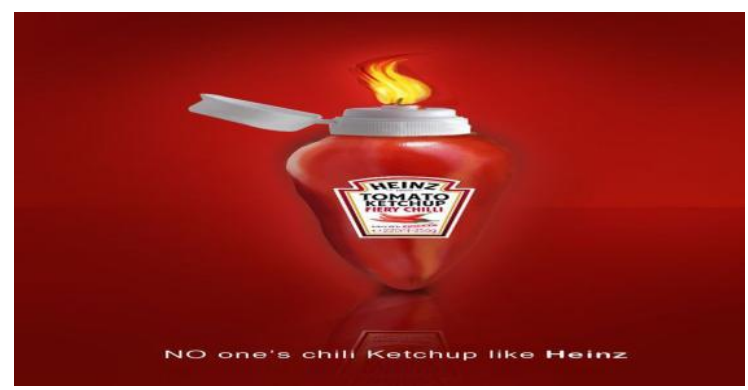

Cognitive analysis:

\begin{tabular}{|c|c|c|}
\hline \multicolumn{2}{|l|}{ Theme } & Heinz \\
\hline \multicolumn{2}{|c|}{ Metaphor } & Ketchup is fire \\
\hline \multicolumn{2}{|l|}{$\mathrm{S}$} & No one's chili Ketchup like Heinz \\
\hline \multicolumn{2}{|l|}{$\mathrm{T}$} & Heinz Tomato Ketchup \\
\hline \multicolumn{2}{|l|}{ SR } & Verbal \\
\hline \multicolumn{2}{|l|}{ TR } & Visual \\
\hline \multicolumn{2}{|l|}{ Modality } & Multimodal \\
\hline \multicolumn{2}{|l|}{ Features } & Source and target are mixed \\
\hline \multicolumn{2}{|l|}{ Type } & Hybrid \\
\hline \multirow{6}{*}{$\begin{array}{l}\text { Image } \\
\text { Scheme }\end{array}$} & Force & blockage, compulsion, attraction ,counterforce \\
\hline & Attribute & strong-weak, dark-bright, warm-bright \\
\hline & Containment & full-empty, in-out \\
\hline & Balance & point balance equilibrium \\
\hline & Space & up-down, center-periphery \\
\hline & multiplicity & part-whole \\
\hline
\end{tabular}

In this image the target is represented visually (Heinz Tomato Ketchup) while the source is represented verbally (No one's chili Ketchup like Heinz).Both domains are presented in different modes. Thus the metaphor in this image is multimodal .The role of the verbal representation of the source' 'No one's chili ketchup like Heinz" is to draw the attention of the audience to the product.

\section{Stop Smoking}

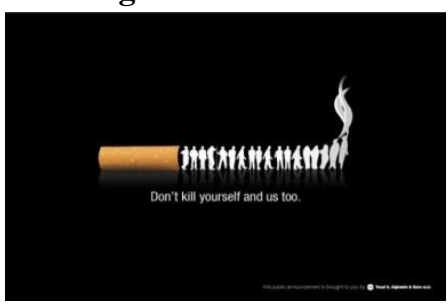




\section{Cognitive analysis:}

\begin{tabular}{|c|c|c|}
\hline \multicolumn{2}{|l|}{ Theme } & Stop Smoking \\
\hline \multicolumn{2}{|l|}{ Metaphor } & Smoking is death \\
\hline \multicolumn{2}{|l|}{$S$} & Smokers gradually turned into an ash \\
\hline \multicolumn{2}{|l|}{$\mathrm{T}$} & Cigarette \\
\hline \multicolumn{2}{|l|}{$\overline{S R}$} & Visual \\
\hline \multicolumn{2}{|l|}{ TR } & Visual \\
\hline \multicolumn{2}{|l|}{ Modality } & Monomodal \\
\hline \multicolumn{2}{|l|}{ Features } & There is a mixture of the source and the target \\
\hline \multicolumn{2}{|l|}{ Type } & Hybrid \\
\hline \multirow{5}{*}{$\begin{array}{l}\text { Image } \\
\text { Scheme }\end{array}$} & Force & compulsion, diversion \\
\hline & Attribute & dark-bright \\
\hline & Containment & in-out \\
\hline & Space & straight-curved ,up-down, left-right, front-back, path \\
\hline & multiplicity & count-mass \\
\hline
\end{tabular}

In this case, it is shown that the target domain is the cigarette whereas the source domain is represented by the smokers. The metaphor in this image is monomodal. The verbal part "don't Kill Yourself and us too" is not part of the ad as both the target and the source are presented visually. The mapping between them is cognitively made, as the audience has the knowledge that smokers affect non-smokers life, as exactly as the way a cigarette can kill people. Hence, the audience make use of their background knowledge to catch the message of this ad which is they have to stop smoking.

\section{RESULT AND DISCUSSION}

The analysis of the Americanand Britishadvertisements indicates many kinds of pictorial metaphor: Multimodal, Monomodal, and borderline cases. The difference between multimodal and monomodal is clear. Multimodal pictorial metaphors contain verbal domain besides the visual domain. A monomdal pictorial metaphor is presented by one mode. In other words, both the source and the target are visual. The borderline cases are put between multimodal and monomodal, so making a continuum between multimodal and monomodal .In borderline cases, the metaphor can only be comprehended when there is a verbal part that does not express any of the two domains, the target or the source.

Moreover, the continuum between the kinds of pictorial metaphor is obvious in identifying each visual advertisement. The American and British pictorial advertisements are 10,5 advertisements for each one.

The main results reveal that metaphors, unlike literal messages, are harder to process andcomprehend and the power of metaphors is noticed in its familiarity and in the interaction between a user and a product.

The table below shows a summary of cognitive analysis of American Pictorial advertisements. Itshows that both American pictorial metaphors and British pictorial metaphors tend to be hybrid specifically (4/5) 80\% in American ones and (3/5) $60 \%$ in British.

\begin{tabular}{|c|c|c|c|c|c|c|c|}
\hline & Metaphor & $\mathbf{S}$ & $\mathbf{T}$ & SR & TR & Modality & Type \\
\hline \multirow{4}{*}{ 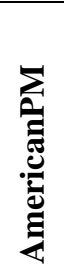 } & $\begin{array}{l}\text { Facebook likeness sign is a } \\
\text { killing knife. }\end{array}$ & The knife & Likeness sign & Visual & Visual & Monomodal & Hybrid \\
\hline & Pear is fish, fish is pear & Fish, Pear & Fridge & Visual & Visual & Borderline case & Hybrid \\
\hline & Cigarette is a bullet & $\begin{array}{l}\text { Quick death } \\
\text { "bullet". }\end{array}$ & $\begin{array}{l}\text { Slow death } \\
\text { "cigarette". }\end{array}$ & $\begin{array}{l}\text { Verbal/ } \\
\text { visual }\end{array}$ & $\begin{array}{ll}\text { visual } & / \\
\text { visual } & \end{array}$ & Multimodal & Simile \\
\hline & The Facebook like ignites a & The lighter. & Likeness sign & Visual & Visual & Monomodal & Hybrid \\
\hline
\end{tabular}




\begin{tabular}{|c|c|c|c|c|c|c|c|}
\hline & riot. & & & & & & \\
\hline & Pepper is fire. & Fire & Pepper & Visual & Visual & Monomodal & Hybrid \\
\hline \multirow[b]{5}{*}{ 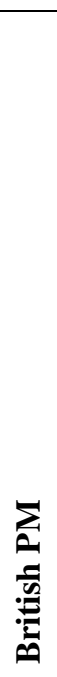 } & $\begin{array}{l}\text { Careless driving can be very } \\
\text { dangerous. }\end{array}$ & The gun & Switch key & Visual & Visual & Monomodal & Hybrid \\
\hline & $\begin{array}{l}\text { Negative words on social } \\
\text { media are kinds of body } \\
\text { violence. }\end{array}$ & $\begin{array}{l}\text { The raised } \\
\text { hand. }\end{array}$ & $\begin{array}{l}\text { The boy in } \\
\text { front of the } \\
\text { screen }\end{array}$ & Visual & Visual & Borderline case & Contextual \\
\hline & Loans are a deep sea. & Sea & Loans & Verbal & Visual & Multimodal & Contextual \\
\hline & Ketchup is fire & $\begin{array}{l}\text { No one's } \\
\text { chili } \\
\text { Ketchup like } \\
\text { Heinz }\end{array}$ & $\begin{array}{l}\text { Heinz Tomato } \\
\text { Ketchup }\end{array}$ & Verbal & Visual & Multimodal & Hybrid \\
\hline & Smoking is death & $\begin{array}{l}\text { Smokers } \\
\text { gradually } \\
\text { turned into } \\
\text { an ash }\end{array}$ & Cigarette & Visual & Visual & Monomodal & Hybrid \\
\hline
\end{tabular}

\section{CONCLUSIONS}

The main conclusions of this paper is that many Advertising depends on pictorial metaphor metaphors which should be designed carefully to help the customer discovers the intended meanings behind both image schema and metaphor. In such metaphors visual part and the verbal reinforcement should be in a balance. It is also concluded that there are some similarities and differences in American and British pictorial metaphor ads.There is a logical relation between the target and the source domains so as to help the audience to catch the intended message. It can be said that the best way to draw the attention of customers is by using visual item with a verbal part.

\section{REFERENCES}

Anaya, M. A. (2008). Changing appearances: magazine advertising layout and design, 1980 /2005 (Unpublished master's thesis). San Jose State University, US.

Baker, S. (1988). The advertiser's manual. New York: Wiley.

Bignell, J. (2002). Media Semiotic: An Introduction. NewYork: Manchester University Press

Black, M. (1979). Models and Metaphors. Ithaca: Cornell UP.

Cacciari, C. (1998). Why do we speak metaphorically? Reflections on the functions of metaphor indiscourse and reasoning.In A. Katz, C. Cacciari, R. W. Gibbs Jr. \&M.Turner, Figurative Language and Thought. Oxford: Oxford University Press.

Carroll, N. (1996). "A Note of Film Metaphor", In Theorizing The moving Image: Cambridge: Cambridge University Press.

Clausner,T.\& Croft, W. (1999). Domains and image schemas. Cognitive Linguistics, 10, 1-31

Cook, G. (1992). The Discourse of Advertising, London: Routledge.

Dą̧browski, J. (2000). 'Metaphors in Advertising Texts: A Cognitive Grammar Analysis'. In Spånberg, S-J., H.Kardela\& G. Porter (eds.), 295-313.

Dyer,G.(1988).Advertising as Communication. London: Routledge.

Evans, V. and Green, M. (2006).Cognitive Linguistics. Edinburgh: Edinburgh University Press.

Forceville, C. (1996). Pictorial Metaphor in Advertising. London: Routledge. 
(2009). Non-verbal and multimodal metaphor in a cognitivist framework: agendas for research. De Gruyter Mouton, 19-45.

Gibbs, R. (1994). The cognitive psychological reality of image schemas and their transformations. In D. Geraerts (ed.): Cognitive Linguistics .Berlin: Mouton de Gruyter.

Goatly, A. (1997).The Language of Metaphors. London: Routledge.

Grady, J. (2007).Foundations of Meaning: Primary Metaphor and Primary Science .Ph.D Dissertation at the university of Bekerley.

Hermerén, L. (1999). English for Sale: A Study of the Language of Advertising. Lund: Lund University Press.

Homer, P, M. (2008). "Perceived Quality and Image: When All Is Not Rosy“. Journal of Business Research, 61 (7),715723.

Johnson, K. and Johnson, H. (1999).Encyclopedic Dictionary of Applied Linguistics. Oxford: Blackwell Publishing.

Johnson, M. (1987).The Body in the Mind: The Bodily Basis of Meaning, Imagination, and Reason. Chicago: Chicago University Press.

(2005). "The Philosophical Significance of Image Schmas" in From Perception to Meaning: Image Schemas in Cognitive Linguistics. Berlin: Mouton de Gruyter. p.p. 15-33

Kaplan, S.(1992) J. "A Conceptual Analysis of Form and Content in Visual Metaphors". Communication $13 \backslash 2$ (1992) 187-209.

Kittay, E. F. (1987). Metaphor: Its Cognitive Force and Linguistic Structure. Oxford:Clarendon press.

Kövecses,Z. (2005). Metaphor in Culture: Universality and Variation. Cambridge: Cambridge University Press.

------ (2010). Metaphor: A Practical Introduction (2nd Edition). Oxford: Oxford University Press.

Kress, G. (2010). Multimodality: A Social Semiotic Approach to Contemporary Communication. London: Routledge.

Lakoff, G. \& Johnson, M. (1980).Metaphors we live by. Chicago: University of Chicago Press.

Lakoff, G. \& M. Turner. (1989). More than cool reason: A field guide to poetic metaphor. New York: Mouton de Gruyter.

MacCormac, E. R.(1985). A Cognitive Theory of Metaphor.Cambridge:MIT.

Martin, J. and Harre, R. (1982): Metaphor in Science, in D. S. Miall (cd.), Metaphor,Sussex: The Harvcster Press.

Morris, R. (1993). Visual rhetoric in political cartoons: A structuralist approach. Metaphor and Symbolic Activity.

Nevett, T.1992. "Differences Between American and British Advertising: Explanations and Implications." Journal of Advertising.

Oakley, T. (2007). "Image Schemas" in The Oxford Handbook of Cognitive Linguistics.Edited by: Geeraerts, Dirk and Cuyckens, Huberts. Oxford: Oxford University Press. p.p. 314-235

Ortony, A., (ed.). (1979). Metaphor and Thought. Cambridge: Cambridge University Press.

Phillips, B., Edward F. and McQuarrie. (2004) Beyond visual metaphor: A new typology of visual rhetoric in advertising. Marketing Theory 4 (1-2): 113-136.

Pieters, R., \& Wedel, M. (2004). Attention capture and transfer in advertising: Brand, pictorial, and text-size effects. Journal of Marketing, 68(2), 36-50.

Pollay, R. (1985) 'The Subsidizing Sizzle: A Descriptive History of Print Advertising,1900-1980', Journal of Marketing 48 (Summer): 24-37.

Stern, B. B. (1990). Beauty and joy in metaphorical advertising: The poetic dimension. Association for Consumer Research.

Sullivan, L. (2008). Hey Whipple, squeeze this: A guide to creating great advertising (Third edition). Hoboken, NJ: Wiley \& Sons, Inc.

Szwedek, Aleksander (2019) “The Image Schema: A Definition.” Styles of Communication.11(1); 9-30.

Tanaka, K. (1994). Advertising Language: A Pragmatic Approach to Advertisements in Britain and Japan. London: Routledge.

Ungerer, F. (2000).Muted metaphors and the activation of metonymies in advertising. In Barcelona, A. (ed.) Metaphor and Metonymy at the Crossroads:A Cognitive Perspective, 321-339. Berlin: Mouton de Gruyter. 
Van Enschot, R., \&Hoeken, H. (2015).The occurrence and effects of verbal and visual anchoring of tropes on the perceived comprehensibility and liking of TV commercials. Journal of Advertising, 44(1), 25-36.

Vestergaard, T. \& Schroder, K. (1985).The Language of Advertising. Oxford: Basil Blackwell.

Weisberg, L.F. (2012).More than Words:Metaphor in the Mind,Brain,and Literature. A Senior Honors Thesis.BrownUniversity.Rhode Island, United States of America.

Werner, W. (1975).Selected Essays on Intermediality .Boston : DRILL RODOPI.

Williamson, J. (1978). Decoding Advertisements. London and Boston, Massachusetts: Marion Boyars. 